\title{
Volatility Transmission from Mature Global Stock Markets to Middle East and North African Stock Markets
}

\author{
Akash Dania (Corresponding author) \\ School of Business \\ Alcorn State University \\ Natchez, MS 39120, USA
}

Tel: 1-601-304-4388 E-mail: adania@alcorn.edu

\author{
John E. Spillan \\ School of Business \\ University of North Carolina at Pembroke \\ Pembroke, NC 28372, USA
}

Tel: 1-910-775-4357Ｅ-mail: john.spillan@uncp.edu

Received: October 23, 2012

Accepted: November 22, 2012

Online Published: November 27, 2012

doi:10.5430/afr.v2n1p19

URL: http://dx.doi.org/10.5430/afr.v2n1p19

\begin{abstract}
The objective of this paper is to model the dynamics of volatility transmission from mature global stock markets of France, Germany, UK and the US to MENA (Middle East and North African) markets of Bahrain, Egypt, Jordan, Kuwait, Lebanon, Morocco, Oman, Qatar, Tunisia, and the United Arab Emirates. GARCH, TGARCH models of returns are estimated to determine evidence of volatility spillover from global mature markets to emerging or less mature markets of MENA region. We find evidence of different level of volatility spillover and leverage effect. This varying response to global stock market shocks reveals that MENA stock markets are not fully integrated with global economy.
\end{abstract}

JEL Classification: C5, F3, F6, G1

Keywords: MENA equity markets, Volatility spillover, GARCH, TGARCH

\section{Introduction}

Over last two decades, emerging and developing economies across the world have achieved high growth in economic and employment activities through political and economic liberalization policies (Collins and Abrahamson, 2006). Bekaert et al. (2006) show that the process of market liberalization, on average, leads to a one percent increase in annual economic growth for emerging and developing economies. They further conclude that leading growth responses are found relative to respective nation's financial institution quality. Although in finance literature there are ample studies discussing relation among liberalization process and economic growth, there lacks comprehensive analysis on how equity market returns of markets in process of liberalization or recently liberalized react to global market returns. Progression of wider integration in international financial markets system is known to increase vulnerability to foreign influences, particularly to reversal in international capital movements, more so during times of financial turmoil (Colins and Biekpe, 2003; Bekaert et al., 2005). Therefore, understanding of volatility transmission from mature markets to emerging and less mature financial markets is as important an issue as understanding of benefits of liberalization. Cross-border contagion may have considerable impact on financial market stability of these recently liberalized equity markets. However, majority of literature on volatility spillover has focused on understanding the dynamics among mature stock markets while ignoring newly liberalized or less mature stock markets appearing on 'investible horizon.'

Among recent addition are the stock markets of Middle East and North Africa (MENA) region. According to EIU (2011) overall near-term GDP growth for MENA region for an otherwise depressed global economy is projected to be around 5\%. So investing in MENA equity markets hold relatively high returns potential. MENA region 
economies have been benefiting from oil revenue generated from rising global energy demand since 2003. Oil revenues have supported growth in regional trade and industrial activity while brining liquidity to MENA financial markets. Political and economic reforms, though heterogeneous in degree, have also accelerated regional economic development. Notable among reform was opening of MENA equity markets to foreign direct investment during early 2000s (Neaime, 2006). Since then, MENA equity markets as foreign and regional investors include MENA region stocks to their portfolio to take advantage of potential diversification benefits. Such was not always the case. Post Second World War, it remained complex for MENA nations to forge ahead in a polarized environment as established by their allies during the cold war (Abdmoulah, 2004). This environment influenced economic and political policies, often resulting in conflicts. Conflicts and economic isolation resulted in economic stagnation for the majority of MENA region. However, with the setting up of the Gulf Cooperation Council in 1981 (UAE, Bahrain, Saudi Arabia, Oman, Qatar, and Kuwait), the Maghreb alliance in 1989 (Morocco, Algeria, Tunisia, Libya, and Mauritania), and the signing of the Euro-Mediterranean partnership in 1995, began a period of political, social, and economic reform for MENA nations. Since then MENA region has progressively been making structural change to its financial institutions while enhancing their efficiency policies (Neaime, 2006).

To examine fundamental characteristics of MENA equity markets, researchers have focused on topics such: the extent of economic and financial integration among MENA region markets (e.g., Dania and Udemgba, 2011; Hammoudeh et al. 2009; Zarour \& Siriopoulos, 2008; Darrat and Pennathur, 2002); regional stock market efficiency (e.g., Abdmoulah, 2009; Civelek, 1991; El-Erian and Kumar; 1995, Smith 2004; Lagoarde-Segot and Lucey 2005); understanding the issue of volatility spillover among domestic sectors (e.g., Hammoudeh, et al., 2009); spillover from US equity market to markets of oil rich nations such as Saudi Arabia and Bahrain (e.g., Abraham and Sayyed, 2005; Alsubaie and Najand, 2008), and spillover among oil, US and Gulf equity markets (e.g., Malik and Hammoudeh, 2007, Chang et al., 2010). Additionally, there have also been studies, which focus on understanding risk component of investing in MENA equity markets (e.g., Girad and Omran, 2007; Girad and Omran, 2003).

However, an area of research, which has received little focus, is dynamics of volatility transmission among MENA equity market and major global equity markets. This issue is important as newly liberalized or in process of liberalizing equity markets of MENA may be susceptible to asymmetric spillovers effects from global equity markets. It is well recognized that amid globalization and liberalization process as markets mature; they are become progressively prone and sensitive to volatility spillovers from global stock markets (e.g., Hamao et al., 1990, King and Wadhwani, 1990, Edward and Susmel, 2001). Regardless of existing research on the behavior of stock prices of stock markets of developed nations, very little is known about the behavior of emerging markets, such as sensitivity to volatility spillovers from global markets. Such an analysis will reveal important and distinct heterogeneity patterns of economies in transition, such as whether they are in embryonic phase, or in phase of low activity, or in an active phase, or have reached maturity (Derrabi et al., 2000). The heterogeneity relates to the size of the market, nature of its fragmentation and segmentation, aggressive growth of listed indices, level of concentration of capital (i.e. whether in hand of few), regulation, liquidity, and uncertainty among investors to invest in these markets for social, behavioral or risk averseness reasons (Derrabi and Leseure, 2005). Important disparities also exist at the market microstructure and the activity level (Bekaert and Harvey, 2002). Investigating these issues for underexplored regions will allow academicians to comprehend the dynamics of stock market, which are heterogeneous in degree of reforms and regulatory changes. Results from this paper will also allow MENA region policy makers understand implications of the transmission and formulate policies to mitigate risk originating from global markets. Results from this paper and understanding of volatility spillover in diverse market scenarios such as those of these MENA markets will also benefit regional and international investors.

Using the GARCH (generalized ARCH) and TGARCH (threshold GARCH) methodology on monthly data (between September 2005 and February 2011) of applicable market index returns we achieve several important results. We find evidence of varying degree of volatility and leverage effect between the returns of MENA equity markets and global equity markets. This is consistent with the contention that MENA markets are heterogeneous in channels of volatility transmission. Hence there still exists some degree of opportunity for international portfolio diversification in the MENA region. These results have important implications for investors, managers, policymakers, and scholars interested in the equity markets of MENA region.

The rest of the paper is organized as follows. Section 2 discusses the theoretical background and development of financial markets in MENA region. Section 3 describes the data. Section 4 details the econometric methodology used, whereas section 5 reports the empirical findings and the results. Finally, section 6 includes the conclusions and managerial implications. 


\section{Literature review}

This section of the literature review briefly discusses two issues concerning this paper. First, we discuss the theoretical aspects on observed asymmetries of returns in financial markets and second, note on recent development of financial markets of MENA region.

\subsection{Theoretical framework}

There is ample evidence in finance literature to suggest that integrated markets should have assets of identical risk command the same expected return irrespective of their location (Bekaert and Harvey, 2003). A corollary to process of integration is how regional markets react to shocks originating in global markets, i.e. whether domestic equity markets react differently to positive as opposed to negative shocks originating in foreign equity market. Conceptually, response asymmetries may arise from different sources (global factors or domestic factors). If equity market returns are symmetric, co-movements between regional and global markets during upturn and downturn are likely to be similar. However, prior evidence suggests that the returns distributions are not always symmetric for developed markets (Harvey and Zhou, 1993), and for emerging markets (Harvey, 1995).

Several reasons have been provided to explain the asymmetries of market returns. For example, it may be influenced by returns expectations investors might have regarding domestic returns with respect to changes in foreign market returns (e.g., Erb et al., 1994; Odier and Solnik, 1993). A small downturn in foreign market could potentially have a relatively larger downturn in domestic market causing asymmetry. The downturn might not be as much due to decline in foreign market but earnings disappointment of domestic firms among investors. Therefore, the asymmetry in this case is from expectations of investors arising from the changes in price of a stock of domestic firm(s), which matters, most to investors rather than the real magnitude of changes in global stock markets.

Information and investor sentiments based on irrelevant or incomplete information may also cause asymmetries. If the information is biased it can prompt irrational trading decisions. Such actions can cause erratic capital inflows or outflows. According to Aitken (1996) institutional investor sentiments towards developing or emerging markets can determine performance prices in these equity markets. The absence of transparency is a notable cause for delayed or incomplete information about these markets (Djankov et al., 2005). Institutional investors frequently lack local information regarding an individual country's fundamentals and may treat these markets uniquely different. Decision bias and the segmented nature of emerging markets (Harvey, 1995) can often lead to asymmetric responses in equity market returns.

Asymmetries may also occur because of the risk factors, which are uniquely priced in each individual equity market due to prevailing domestic business environment. Fama and French (1992) have argued that market returns are not completely explained by CAPM beta and as a result there exists multidimensional risk associated with individual equity price. One dimension of the risk is the unidentified danger that persists in stock prices and markets at large. The relationship between unidentified components of risk and equity returns may not be linear and therefore can lead to dissimilar positive and negative returns (Downs and Ingram, 2000; Pettengill et al., 1995; Fletcher, 2000).

Another aspect for asymmetric reaction is also explained from the behavioral viewpoint of investor psychology. Investors, in general, have been known to be more concerned about market downturns than upturns, due to inherent risk-aversion characteristic. This characteristic is reflected in equity pricing, causing greater volatility during times of market downturns than upturns. There is ample evidence on momentum and reversals, which suggests the asymmetric effect of investor sentiments on the stock market (e.g. Hong et al., 2000; Hong and Stein, 1999). The asymmetric effect of sentiments on the equity market is ascribed to limits to arbitrage (Brown and Cliff, 2004) and overconfidence (Gervais and Odean, 2001; Daniel et al., 1998). Price movement asymmetries have been studied and documented for Asian markets (Bahng and Shin, 2003), Australian equity markets (Iorio and Faff, 2000), EMS exchange rates (Laopodis, 2001), commodity markets (Karrenbrock, 1991), goods markets (Peltzman, 2004), and real and underground output in New Zealand (Giles, 1999).

It is now well known that newly emerging equity markets, such as those in MENA region differ in characteristics than equity returns of developed capital markets (Harvey, 1995). The distinguishing features of the returns of these newly formed or emerging markets are usually higher average returns, low correlations with developed market returns, more predictable returns and higher volatility. An examination of the volatility spillover process enhances the understanding of information transmission between international markets. The research of how one equity market impact another is at the heart of investments and diversification (Bekaert, Hodrick and Zhang, 2009). 


\subsection{Development of financial markets in MENA region}

When investigating the financial markets of the MENA region, it is easy to distinguish economies based on their natural resources. There are the oil exporting economies such as Bahrain, Kuwait, Oman and the United Arab Emirates, and then the oil-deprived such as Egypt, Jordan, Morocco, Lebanon, Jordan, Qatar and Tunisia. Presence of oil contributes extensively to the financial wealth and liquidity of financial markets of oil exporting nations (Bontis, 2004) while benefiting the entire region. Governments of the energy rich nations have invested significantly in non-oil based sectors, infrastructure and education which have lead to demand for sophisticated and high quality products, and skilled manpower attributing to growth of non-oil related industry in the entire MENA region (Zineldin, 2002). With a surge in non-oil based sector, MENA economies are fast catching up and rapidly participating in regional economic expansion and globalization process (Hirata et al., 2004). This new business environment in MENA region is encouraging domestic and foreign investors to invest via financial markets rather than the traditional banking sectors. As MENA region economies shift from an oil based economy to service or manufacturing based economy, there has also been a general shift in leverage preference of regional governments in promoting equity based financing for projects and companies.

Stock markets in the MENA region, historically, were less important in channeling financial funds (Neaime, 2006). Traditionally, a fairly developed system of commercial banking system channelized funds from savers to borrowers. Since the late 1990s, several MENA nations have embarked on process of political reforms and financial sector liberalization. National stock markets of these nations are fast replacing the traditional banking system as source of investment and foreign direct investment (Naceur et al., 2008). An interesting observation regarding the MENA region is the level of foreign direct which remains unevenly distributed. According to UNDP (2002), more than 80 percent of FDI in MENA region is concentrated in Saudi Arabia, Egypt, Tunisia, Bahrain, and Morocco. Globalization and privatization, though necessary are not enough for economic growth as noted by Gentzoglanis (2007). Other reasons of this disparity can be attributed to political instability. For example, Lebanon, Algeria, Kuwait, and Libya, experienced extended periods of political instability during 1980s and 1990s precluding and often discouraging regional and foreign investment (Eid and Paua, 2002). Then there remain other impediments such as restrictions on foreign ownership and slow pace of reforms and privatization of tightly controlled government enterprises (Creane et al., 2004).

Regional economic integration is being promoted to reduce the level of risk attached to trading and investment activity (Hanson, 1998). The Gulf Cooperation Council in 1981 (UAE, Bahrain, Saudi Arabia, Oman, Qatar, and Kuwait) and the Maghreb alliance in 1989 (Morocco, Algeria, Tunisia, Libya, and Mauritania) have been established in the MENA region. Economic integration also encourages efficiency allocation of production factors and a more effective division of labor ( $\mathrm{Wu}$ and Chen, 2004). Other advantage of economic integration is reduction of uncertainties associated with local governance and the planning system that would otherwise deter foreign investment (Phelps and Jones, 2000). Like the European Union, the GCC, having achieved convergence on several macroeconomic indicators, are paving the groundwork for formation of a monetary union (Espinoza et al. 2010).

\section{Data and Descriptive Statistics}

For this study we obtain monthly data between September 2005 and February 2011. As a proxy for foreign markets we include market returns of France, Germany, UK and the US. To assess the global integration of the MENA markets, we include corresponding data for 10 major MENA markets. These are the markets of Bahrain, Egypt, Jordan, Kuwait, Lebanon, Morocco, Oman, Qatar, Tunisia and the UAE. Our data is sourced from the MSCI Barra database. To eliminate local currency effect, we use all performance indices in US dollar terms. We compute the continuously compounded returns for all indices.

Table 1 reports the descriptive statistics for variables. From this table we can observe that the mean returns for Egypt, Kuwait, Lebanon, Morocco, Tunisia, UK, US, France, and Germany are positive, whereas for all other markets is negative. The positive average returns may be attributed to the overall growth in these markets during the sample period. Further, all maximums are positive and minimums are negative. We also note that the returns for Bahrain, Egypt, Kuwait, Lebanon, Qatar and the U.A.E report a higher Standard Deviation compared to sample global markets. This is indicative of relatively higher volatility in the returns of these sample MENA market. The presence of negative skewness in our sample indicates a distribution with an asymmetric tail extending towards more negative values. Only Lebanon, Morocco and Tunisia report a positive skewness. A large Kurtosis figure ( $>3$ ) is also observed, indicating a relatively peaked distribution. Only Kuwait has Kurtosis below 3. Observation of these Skewness and Kurtosis characteristics further motivate the use of time-series methodology for analysis.

Insert Table 1 about here 
Table 2 summarizes the coefficient of correlation among the variables of interest. The level of correlations between sample MENA market returns and developed market returns is moderate to low. These figures seem consistent with our earlier discussion that there exist inherent comparative differences between the MENA markets and developed markets economic environment. In summary, moderate to low correlations among these variables suggest that each variable represents unique expectations of their individual market participants.

Insert Table 2 about here

\section{Econometric Methodology}

To test for volatility spillover effect, we utilize a GARCH approach. GARCH framework enables estimation of the variance of the sample series at a particular point of time. GARCH is parsimonious, and avoids over-fitting, which consequently is less likely to violate conditions of non-negativity (Enders 2003). We incorporate a GARCH $(1,1)$ model to test for volatility spillover effect. A GARCH $(1,1)$ allows the conditional variance to be dependent not only on its past conditional variance, but also past innovations. The test for volatility spillover from each global equity market to the included sample MENA equity market returns can be set by extracting residuals from individual global market returns and then applying as independent variable in the conditional volatility equation for respective (each of the) MENA market returns. Basic GARCH $(1,1)$ specification can be expressed as following:

$$
\begin{aligned}
& y_{t}=c+\tau y_{t-1}+\varepsilon_{t}, \varepsilon_{\mathrm{t}} \sim \mathrm{N}\left(0, \sigma_{\mathrm{t}}^{2}\right) \\
& h_{t}=\alpha_{0}+\alpha_{1} \varepsilon_{t-1}^{2}+\beta_{1} h_{t-1}
\end{aligned}
$$

Equation (1) is the mean equation and equation (2) is the conditional variance equation. $y_{t}$ is the return on MENA market of interest, $c$ is the intercept, $y_{\mathrm{t}-1}$ is the previous period return of the same MENA market of interest and $\varepsilon_{\mathrm{t}}$ is the white noise error term. $h_{\mathrm{t}}$ is the conditional variance. Equation (2) gives the basic volatility model, which captures heteroscedasticity property in returns series of MENA market of interest. News about volatility from the previous period, measured as the lag of the squared residual from the mean equation is the ARCH term (measured by $\alpha_{1}$ ) and the last period's forecast variance is the GARCH term (measured by $\beta_{1}$. To integrate spillover effect from global market return, its extracted residuals are included as regressors in the volatility equation. The specification for GARCH $(1,1)$ spillover equation can be expressed as following:

$$
h_{t(\text { Spillover })}=\alpha_{0}+\alpha_{1} \varepsilon_{t-1}^{2}+\beta_{1} h_{t-1}+\psi \xi_{t-1}^{2}
$$

Where $\alpha_{0}>0, \beta_{1} \geq 0, \alpha_{1} \geq 0$, and $\mathcal{E}_{\mathrm{t}-1}^{2}$ is the lagged squared shock of MENA market of interest and provides the news about volatility from the previous period. It is measured as the lag of the squared residual from the mean equation, and $\xi_{\mathrm{t}-1}{ }^{2}$ is the lagged squared shock extracted from the reference global market returns series of interest. The coefficient $\psi$ represents volatility spillover coefficient measuring the extent and behavior of volatility spillover effect.

Despite the obvious success of ARCH and GARCH parameterization, these models do not capture the asymmetric news effect or the leverage effect discovered by Black (1976), Nelson (1991), Engle and Ng (1993), Golsten et al. (1993). The asymmetric effect reflects the pragmatic fact that downward movements in market returns are followed by higher volatilities than upward movements of the same magnitude. Statistically, the leverage effect occurs when and unexpected drop in market returns (bad news) increases observed volatility more than an unexpected increase in market returns (good news). To overcome this shortcoming we use a TGARCH approach as the model captures the leverage effect in quadratic form. The specification for a TGARCH $(1,1)$ is given below:

$$
\begin{aligned}
& y_{t}=c+\tau y_{t-1}+\varepsilon_{t} \\
& h_{t}=\alpha_{0}+\beta_{1} h_{t-1}+\alpha_{1} \varepsilon_{t-1}^{2}+\alpha_{2} \varepsilon_{t-1}^{2} d_{t-1}
\end{aligned}
$$

Where $\varepsilon_{t-1}^{2}$ is the lagged square residual of the MENA market return of interest and $d_{\mathrm{t}}$ is the dummy variable where $d_{\mathrm{t}}=1$ if $\varepsilon_{\mathrm{t}-1}<0$ (bad news) and $d_{\mathrm{t}}=0$ if $\varepsilon_{\mathrm{t}-1}>0$ (good news). $\alpha_{2}$ is the coefficient that takes leverage effect into consideration. If $\alpha_{2}$ is positive, it implies that a negative shock or bad news will increase volatility by more than it would increase with a positive shock. Similarly if it is negative, the volatility will increase more with a positive shock, than it would with a negative shock. To capture the spillover effect from reference global market return series to returns of corresponding MENA market returns series of interest using a TGARCH model. The conditional volatility equation takes the following form: 


$$
h_{t}=\alpha_{0}+\beta_{1} h_{t-1}+\alpha_{1} \varepsilon_{t-1}^{2}+\alpha_{2} \varepsilon_{t-1}^{2} d_{t-1}+\psi_{1} \xi_{t-1}^{2}+\psi_{2} \xi_{t-1}^{2} d_{t-1}
$$

Where $\xi_{t-1}^{2}$ is the lagged squared residual from reference global market returns series and $\psi 2$ captures the leverage effect on the volatility of the MENA market series return of interest. If it is positive, then we can assume that a large positive shock in reference global market returns series will result in larger observed volatility in returns of the MENA market series returns of interest then when compared to negative shocks in the corresponding global market returns.

\section{Estimation Results}

We first estimate a GARCH $(1,1)$ (equations 1 and 2) on individual global market returns (i.e. France, Germany, UK, and the US) and extract the residuals in order to introduce in variance equation of MENA markets. From the basic GARCH model we observe that both GARCH terms, i.e. $\beta$, and the ARCH term i.e., $\alpha$ are significant for all series. Further, $\alpha+\beta$ is very close to 1 in all series indicating that volatility shocks in these series are persistent (Note 1).

We now estimate volatility spillover by introducing the residuals from global market returns in the variance equation of MENA market return series. Tables 3 report the result of the spillover effect of market returns of France on MENA equity markets. $\Psi$ represents the volatility spillover coefficient. It can be observed from Tables 3 that $\alpha_{1}$ and $\beta$ coefficients are significant for Kuwait, Lebanon, Qatar, Tunisia and UAE market returns indicating an evidence of $\mathrm{ARCH}$ and GARCH structure in returns of these returns series. Also, a negative $\alpha_{1}$ is observed for Kuwait, Tunisia and the UAE. The negative sign indicates that volatility increases when past innovations are negative. All other $\alpha_{1}$ coefficients, which are significant in the series, are observed positive. $\Psi$ is positive and significant for Kuwait, Morocco and Tunisia equity market returns indicating that there is evidence of volatility spillover from market returns of France. Further, the positive sign also indicates that the return shocks originating in equity market of France increase the volatility among the returns of these MENA markets. A significant yet negative sign is observed for Lebanon. This indicates the opposite, i.e. shocks originating in equity market of France actually decrease the volatility in market returns of Lebanon.

\section{Insert Table 3 about here}

Tables 4 report the result of the spillover effect of market returns of Germany on MENA equity markets. $\Psi$ represents the volatility spillover coefficient. It can be observed from Table 4 that $\alpha_{1}$ and $\beta$ coefficients are significant for Kuwait, Lebanon, Tunisia and the UAE market returns indicating an evidence of ARCH and GARCH structure in returns of these returns series. A negative $\alpha_{1}$ is observed for Kuwait, Tunisia and the UAE. The negative sign indicates that volatility increases when past innovations are negative. All other $\alpha_{1}$ coefficients, which are significant in the series, are observed positive. $\Psi$ is positive and significant for Kuwait, Morocco, Oman and Tunisia equity market returns indicating that there is evidence of volatility spillover from market returns of Germany. Further, the positive sign indicates that the return shocks originating in equity market of Germany increase the volatility among the returns of Kuwait, Morocco, Oman and Tunisia.

\section{Insert Table 4 about here}

Now we report the spillover effect of market returns of UK on sample MENA equity market returns. It can be observed from Tables 5 that $\alpha_{1}$ and $\beta$ coefficients are significant for Egypt, Kuwait, Lebanon, Qatar, Tunisia, and the UAE market returns indicating an evidence of ARCH and GARCH structure in returns of these returns series. A negative $\alpha_{1}$ is observed for Kuwait, Lebanon, Tunisia and the UAE. The negative sign indicates that volatility increases when past innovations are negative. The spillover coefficient, $\Psi$ is positive and significant for Egypt, Kuwait, Morocco, and Tunisia equity market returns indicating that there is evidence of volatility spillover from market returns of UK to these markets. Further, the positive sign indicates that the return shocks originating in UK equity market increase the volatility among the returns of Kuwait, Morocco, Oman and Tunisia.

\section{Insert Table 5 about here}

Tables 6 reports the result of the spillover effect of market returns of US on sample MENA equity markets. From Tables 6 it can be observed that $\alpha_{1}$ and $\beta$ coefficients are significant for Kuwait, Lebanon, Qatar, Tunisia, and the U.A.E market returns. A negative $\alpha_{1}$ is observed for Kuwait, Tunisia and the UAE, indicating that volatility increases in these markets when past innovations are negative. The spillover coefficient, $\Psi$ is positive and significant for Kuwait and Tunisia equity market returns indicating that there is evidence of volatility spillover from market returns of US to these markets. Further, the positive sign indicates that the return shocks originating in US equity market increase the volatility among the returns of Kuwait and Tunisia. 
Insert Table 6 about here

At this point, we shift our attention on understanding the results from TGARCH estimates. This model not only provides information on whether the effect of shock from originating from MENA market's own return is asymmetric (i.e. reported by $\alpha_{2}$ ) but also provides information on whether the effects of shocks from global markets are asymmetric (reported by $\psi_{2}$ ). Coefficient $\psi_{l}$ provides information about the spillover effect from global market returns and $\psi_{2}$ captures the asymmetric effect. A significant $\alpha_{2}$ indicates that the effects from returns of MENA market of interest's own shock are asymmetric. Table 7 reports the TGARCH results with France as the global equity market. $\alpha_{2}$ are positive and significant for Bahrain, Jordan, Kuwait, Lebanon, and Qatar indicating the volatility tends to increase more asymmetrically, in response to its own negative shock. $\psi_{2}$ for case of Tunisia is found to be positive and significant, which indicates that when there is bad news (negative shock) in French equity market, the volatility of returns in Tunisian market returns is more than what it would have with a positive shock (good news) of same magnitude.

Insert Table 7 about here

Table 8 reports the TGARCH results with Germany as the global equity market. $\alpha_{2}$ are positive and significant for Lebanon and Qatar indicating the volatility tends to increase more asymmetrically, in response to its own negative shock. $\psi_{2}$ for case of Kuwait and Oman is found to be positive and significant, which indicates that when there is bad news (negative shock) in German equity market, the volatility of returns in Kuwaiti and Omani equity market returns is more than what it would have with a positive shock (good news) of same magnitude.

\section{Insert Table 8 about here}

Table 9 reports the TGARCH results with UK as the global equity market. In this case, $\alpha_{2}$ are positive and significant for Bahrain, Lebanon, Qatar, and Tunisia indicating the volatility tends to increase more asymmetrically, in response to its own negative shock. $\psi_{2}$ for case of Tunisia and the UAE is found to be positive and significant, which indicates that when there is bad news (negative shock) in UK equity market, the volatility of returns in Tunisian and the UAE equity market returns is more than what it would have with a positive shock (good news) of same magnitude.

Insert Table 9 about here

Table 10 reports the TGARCH results with US as the global equity market. $\alpha_{2}$ are positive and significant for Bahrain, Kuwait, Qatar, and Tunisia indicating the volatility tends to increase more asymmetrically, in response to its own negative shock. $\psi_{2}$ for case of Tunisia is found to be positive and significant, which indicates that when there is bad news (negative shock) in US equity market, the volatility of returns in Tunisian market returns is more than what it would have with a positive shock (good news) of same magnitude.

\section{Insert Table 10 about here}

\section{Conclusions and managerial implications}

In contemporary global markets, information is now shared more intensively and acted on across major global equity markets. This causes markets to become increasingly integrated. The political and financial reforms along with globalization, and advances in information technology have dramatically changed the structure of MENA region financial markets. In an integrated market, investors can share their consumption risk efficiently, which in turn decreases the costs of capital firms, hereby stimulating investment and economic growth. In this study, we use a GARCH methodology to determine whether volatility spills over from major world markets to the equity markets of MENA region. Inserting the residuals from major world markets to the volatility equations of the sample MENA equity returns does this. There is evidence of significant and positive spillover from France to Kuwait, Morocco, and Tunisia. The positive relationship indicates that when volatility in France increases, volatility in these markets also increases. The relationship is significant and negative for case of Lebanon indicating that volatility in France increases, volatility in Lebanon decreases. For case of Germany, there is indication of positive relation for markets of Kuwait, Morocco, Oman, and Tunisia. For case of UK there is evidence of positive spillover to markets of Egypt, Kuwait, Morocco, and Tunisia. Finally, for the case of U.S there is evidence of positive spillover on market returns of Kuwait and Tunisia.

To test the presence of asymmetry of volatility transmission or the leverage effect we use TGARCH methodology. A positive and significant coefficient capturing news effect will indicate that when there is bad news (negative shock) in foreign equity market, the volatility of returns in domestic market returns is more than what it would have with a positive shock (good news) of same magnitude. In case of France, a significant and positive relation is found for 
Tunisia and in case of Germany, it is observed for the markets of Kuwait and Oman. Similarly, for UK positive relation is found for UAE and for the US, positive significant relation is found for Tunisia.

Overall, there is a mixed evidence of global spillover from global market to equity markets of MENA region. This is consistent with the contention that individual financial markets of the MENA region exhibit primarily their domestic business conditions. Hence there still exists a limited opportunity for international portfolio diversification in the equity markets of MENA region which may have been overlooked by international investors. However, this condition may change with the ongoing political and financial reforms and increase in foreign direct investment from within and outside the region. The findings from this paper have important implications for investors, managers, policymakers, and scholars interested in the equity markets of MENA countries. Among the conclusions of this paper is that financial markets liberalization does not bring immediate integration with global markets equally, rather this is a process which occurs in the long run. However, the question whether the process of market liberalization benefited individual MENA markets and the region has largely been ignored. However, we leave this as a topic for future research.

\section{References}

Abdmoulah, W. (2010). Testing the evolving efficiency of Arab stock markets. International Review of Financial Analysis, 19 (1), 25-34. http://dx.doi.org/10.1016/j.irfa.2009.11.004.

Abraham A., \& Seyyed, F.J. (2006). Information transmission between the Gulf equity markets of Saudi Arabia and Bahrain. Research in International Business and Finance, 20 (3), 276-285. http://dx.doi.org /10.1016/j.ribaf.2005.05.007.

Aitken, B. (1996). Have Institutional Investors Destabilized Emerging Markets? International Monetary Fund Working paper, 96/34, Washington DC. http://dx.doi.org /10.1111/j.1465-7287.1998.tb00510.x

Alsubaie, A., \& Najand, M. (2009). Trading volume, time-varying conditional volatility, and asymmetric volatility spillover in the Saudi stock market. Journal of Multinational Financial Management, 19 (2), 139-159. http://dx.doi.org/10.1016/j.mulfin.2008.09.002

Bahng, J. S., \& Shin, S. (2003). Do Stock Price Indices Respond Asymmetrically? Evidence from China, Japan and South Korea. Journal of Asian Economics, 14, 541-563. http://dx.doi.org/10.1016/S1049-0078(03)00094-0

Bekaert, G., \& Harvey, C.R. (2003). Emerging markets finance. Journal of Empirical Finance, 10, 3-55. http://dx.doi.org/10.1016/S0927-5398(02)00054-3

Bekaert, G., Harvey, C. R., \& Christian T., L. (2004). Does Financial Liberalization Spur Growth? AFA 2002 Atlanta Meetings. [Online] Available at SSRN: http://ssrn.com/abstract=264818 or http://dx.doi.org/10.2139/ssrn.264818

Bontis, N. (2004). National intellectual capital index A United Nations initiative for the Arab nations. Journal of Intellectual Capital, 5 (1), 13-39. http://dx.doi.org/10.1108/14691930410512905

Brown, G. W., \& Cliff, M.T. (2005). Investor Sentiment and Asset Valuation. Journal of Business, 78(2), 405-440. http://dx.doi.org/10.1086/427633

Chang, C., McAleer, M., \& Tansuchat, R. (2010). Analyzing and forecasting volatility spillovers, asymmetries and hedging in major oil markets. Energy Economics, 32 (6), 1445-1455. http://dx.doi.org/10.1016/j.eneco.2010.04.014

Civelek, M.A. (1991). Stock market efficiency revisited: evidence from the Amman stock exchange. The Middle East Business and Economic Review, 3, 27-31.

Creane, S., Goyal, R., Mobarak, A.M., \& Sab, R. (2004). Financial sector development in Middle East and North Africa. IMF Working Paper, 04/102, Washington, DC. [Online] Available at SSRN: http://ssrn.com/abstract=879026

Collins, D., \& Abrahamson, M. (2006). Measuring the cost of equity in African financial markets. Emerging Markets Review, 7, 67-81. http://dx.doi.org/10.1016/j.ememar.2005.06.003

Collins D., \& Biekpe, N. (2003). Contagion: a fear for African equity markets? Journal of Economics \& Business, 55(5), pp. 405-426. http://dx.doi.org/10.1016/S0148-6195(03)00020-1

Darrat A. \& Pennathur, F. (2002). Are the Arab Maghreb countries really integratable? Some evidence from the theory of cointegrated systems. Review of Financial Economics, 11 (2), 79-90. http://dx.doi.org/10.1016/S1059-0560(02)00105-3

Derrabi, M., de Bodt, E., \& Cobbaut, R. (2000). Microstructure changes and stock price behavior, evidence from Casablanca stock exchange. NASDAQ-Notre Dame Microstructure Conference, Paris.

Derrabi, M., \& Leseure, M. (2005). Global asset allocation: risk and return trade-off on emerging stock markets. In Risk Management in Emerging Markets, Palgrave Macmillan Publishers. New York. 
Djankov, S., LaPorta, R., Lopez-de-Silanes, F., \& Shleifer, A. (2005). The Law and Economics of Self-Dealing. National Bureau of Economic Research, Working Paper 11, Cambridge, MA. http://dx.doi.org/10.1016/j.jfineco.2007.02.007

Dania, A., \& Udemgba, B. (2011). Integration of the Middle East and North African Stock Markets with Global Stock Markets. International Journal of the Academic Business World, Fall 5(2), 57-68.

Downs, T. W., \& Ingram, R.W. (2000). Beta, Size, Risk and Return. The Journal of Financial Research, 23(3), 245-260.

Economic Intelligence Unit, (2011). 'World investment prospects to 2011 foreign direct investment and the challenge of political risk', EIU report. [Online] Available: http:// graphics.eiu.com/upload/WIP_2007_WEB.pdf

Edwards, S., \& Susmel, R. (2001). Volatility dependence and contagion in emerging equity markets. Working paper, IASE Seminar, Buenos Aires, Argentina. http://dx.doi.org/10.1016/S0304-3878(01)00172-9

Eid, F., \& Paua, F. (2002). Foreign Direct Investment in the Arab World: The Changing Investment Landscape. Global Competitiveness Report, World Economic Forum.

El-Erian, M.A, \& Kumar, M.S. (1995). Emerging equity markets in Middle Eastern countries. IMF Staff Paper, 42, 313-343. http://dx.doi.org/10.5089/9781455224296.002.A001

Erb, C. B., Harvey, C. R., Viskanta, T.E. (1994). Forecasting International Equity Correlations. Financial Analysts Journal, 50, 32-45. http://dx.doi.org/10.2469/faj.v50.n6.32

Fama, E. F. \& French, K.R. (1992). The Cross-Section of Expected Stock Returns. Journal of Finance, 47, 427-465. http://dx.doi.org/10.1111/j.1540-6261.1992.tb04398.x

Fletcher, J. (2000). On the Conditional Relationship between Beta and Return in International Stock Returns. International Review of Financial Analysis, 9, 235-245. http://dx.doi.org/10.1016/S1057-5219

Gentzoglanis, A. (2007). Financial integration, regulation and competitiveness in Middle East and North African countries. Managerial Finance, 33, 461-467. http://dx.doi.org/10.1108/03074350710753744

Gervais, S., \& Odean, T. (2001). Learning to be Overconfident. Review of Financial Studies, 14, 1-28. http://dx.doi.org/10.1093/rfs/14.1.1

Giles, D. E. A. (1999). The Rise and fall of the New Zealand Underground Economy: Are the Responses Symmetric? Applied Economics Letters, 6, 185-189. http://dx.doi.org/10.1080/135048599353609

Hamao, Y., Masulis, R., \& Ng, V. (1990). Correlations in price changes and volatility across international stock markets. The Review of Financial Studies, 3, 281-307. http://dx.doi.org/10.1093/rfs/3.2.281

Hammoudeh, S. M.,Yuan, Y., \& McAleer, M. (2009). Shock and volatility spillovers among equity sectors of the Gulf Arab stock markets. The Quarterly Review of Economics and Finance, 49 (3), 829-842. http://dx.doi.org/10.1016/j.qref.2009.04.004

Harvey, C. (1995). Predicting risk and return in Emerging markets. Review of Financial Studies, 8, 773-816. http://dx.doi.org/10.1093/rfs/8.3.773

Harvey, C. R., \& Zhou, G. (1993). International Asset Pricing with Alternative Distributional Specifications. Journal of Empirical Finance, 1(1), 107-131. http://dx.doi.org/10.1016/0927-5398(93)90007-E

Hirata, H., Kim, S.H., \& Kose, M.A. (2004). Integration and Fluctuations: The Case of MENA. Emerging Markets Finance and Trade, 40 (6) 48-67.

Hong, H., \& Stein, J.C. (1999). A Unified Theory of Underreaction, Momentum Trading and Overreaction in Asset Markets. Journal of Finance, 54, 2143-2184. http://dx.doi.org/10.1111/0022-1082.00184

Hong, H., Lim, T., \& Stein, J.C. (2000). Bad News Travels Slowly: Size, Analyst Coverage and the Profitability of Momentum Strategies. Journal of Finance, 55, 265-292. http://dx.doi.org/10.1111/0022-1082.00206

Iorio, A. D., \& Faff, R. (2000). An Analysis of Asymmetry in Foreign Currency Exposure of the Australian Equities Market. Journal of Multinational Financial Management, 10, 133-159. http://dx.doi.org/10.1016/S1042-444X(99)00024-9

Karrenbrock, J. D. (1991). The Behavior of Retail Gasoline Prices: Symmetric or Not? Federal Reserve Bank of St. Louis Bulletin, 73, 19-29.

King, M., \& Wadhwani, S. (1990). Transmission of volatility between stock markets. Review of Financial Studies, 3(1), 5-33. http://dx.doi.org/10.1093/rfs/3.1.5

Lagoarde-Segot, T., \& Lucey, B. (2005). Stock market predictability in the MENA: Evidence from new variance ration tests and technical trade analysis. Discussion Paper no 92, Trinity College Dublin. http://dx.doi.org/ $10.2139 /$ ssrn.792204 
Laopodis, N. T. (2001). Time-Varying Behavior and Asymmetry in EMS Exchange Rates. International Economic Journal, 15(4), 81-94. http://dx.doi.org/10.1080/10168730100000054

Malik, F., \& Hammoudeh, S. (2007). Shock and volatility transmission in the oil, US and Gulf equity markets. International Review of Economics \& Finance, 16 (3), 357-368. http://dx.doi.org/10.1016/j.iref.2005.05.005

Naceur, S. B., Ghazouani, S., \& Omran, M. (2008). Does stock market liberalization spur financial and economic development in the MENA region? Journal of Comparative Economics, 36 (4), 673-693. http://dx.doi.org/10.1016/j.jce.2007.12.002

Neaime, S. (2006). Volatilities in Emerging MENA Stock Markets. Thunderbird International Business Review, 48 (4), 455-484. http://dx.doi.org/10.1002/tie.20105

Neaime, S. (2006). 'Portfolio Management and Financial Market Integration of Emerging MENA Stock Markets', In Global Stock Markets and Portfolio Management, Palgrave and Macmillan, London, United Kingdom, 4, 37-54. http://dx.doi.org/10.1002/tie.20105

Nelson, D. B. (1991). 'Stationarity and Persistence in the GARCH $(1,1)$ Model', Economic Theory, 6, 318-334. http://dx.doi.org/10.1017/S0266466600005296

Odier, P., \& Solnik, B. (1993). Lessons for International Asset Allocation. Financial Analysts Journal, 49, 63-77. http://dx.doi.org/10.2469/faj.v49.n2.63

Peltzman, S. (2000). Prices Rise Faster than They Fall. Journal of Political Economy, 108(3), 466-502.

Pettengil, G., Sundaram, S., \& Mathur, I. (1995). The Conditional Relation between Beta and Return. Journal of Financial and Quantitative Analysis, 30, 101-116. http://dx.doi.org/10.4067/S0717-68212004012200003

Zarour, B., \& Siriopoulos, C.P. (2008). Transitory and permanent volatility components: The case of the Middle East stock markets. Review of Middle East Economics and Finance, 4, 1-14. http://dx.doi.org/10.2202/1475-3693.1060

Zineldin, M. (2002). Globalization, strategic co-operation and economic integration among Islamic/Arab countries. Management Research News, 25 (4), 35 - 61. http://dx.doi.org/10.1108/01409170210783188

Notes

Note 1. Basic GARCH $(1,1)$ results are not reported in a table as the focus is on spillover effect, but are available on request.

Note 2. The authors are very grateful to the anonymous referees for useful comments.

Table 1. Descriptive Statistics

Table 1 reports descriptive statistics of continuously compounded monthly returns for all indices between September 2005 and February 2011. In table are MENA markets of Bahrain (BAH), Egypt (Egypt), Jordan (JOR), Kuwait (KUW), Lebanon (LEB), Morocco (MOR), Oman (OMA), Qatar (QTR), Tunisia (TUN), United Arab Emirates (UAE). Also included are the global reference markets of France (FRA) and Germany (GER), UK (UK) and US (US).

\begin{tabular}{llllllll}
\hline & Mean & Median & Maximum & Minimum & Std. Dev. & Skewness & Kurtosis \\
\hline BAH & -0.0180 & -0.0118 & 0.1746 & -0.2835 & 0.0805 & -0.5323 & 4.8835 \\
EGY & 0.0064 & 0.0146 & 0.2654 & -0.3262 & 0.1051 & -0.4801 & 3.7562 \\
JOR & -0.0125 & -0.0064 & 0.1536 & -0.2317 & 0.0637 & -0.7525 & 4.9433 \\
KUW & 0.0006 & 0.0065 & 0.2102 & -0.1904 & 0.0822 & -0.1800 & 2.9307 \\
LEB & 0.0096 & 0.0045 & 0.4769 & -0.2260 & 0.1120 & 1.2479 & 7.3706 \\
MOR & 0.0158 & 0.0186 & 0.2393 & -0.1555 & 0.0702 & 0.0706 & 3.9387 \\
OMA & -0.0019 & 0.0090 & 0.1343 & -0.2986 & 0.0705 & -1.2323 & 6.5020 \\
QAT & -0.0026 & 0.0046 & 0.2332 & -0.2648 & 0.0997 & -0.1977 & 3.3707 \\
TUN & 0.0093 & 0.0122 & 0.2417 & -0.1747 & 0.0615 & 0.3283 & 6.0256 \\
UAE & -0.0201 & -0.0209 & 0.2405 & -0.3336 & 0.1094 & -0.0526 & 3.6839 \\
UK & 0.0017 & 0.0072 & 0.1324 & -0.1913 & 0.0590 & -0.5162 & 4.2403 \\
US & 0.0026 & 0.0115 & 0.0943 & -0.1725 & 0.0500 & -0.8848 & 4.2735 \\
FRA & 0.0036 & 0.0086 & 0.1448 & -0.2243 & 0.0724 & -0.6756 & 3.5766 \\
GER & 0.0075 & 0.0151 & 0.1539 & -0.2297 & 0.0751 & -0.7720 & 3.7631 \\
\hline
\end{tabular}


Table 2. Coefficient of Correlations Among Variables of Interest

Table 2 reports the coefficient of correlation among of continuously compounded monthly returns for all indices between September 2005 and February 2011. In table are MENA markets of Bahrain (BAH), Egypt (Egypt), Jordan (JOR), Kuwait (KUW), Lebanon (LEB), Morocco (MOR), Oman (OMA), Qatar (QTR), Tunisia (TUN), United Arab Emirates (UAE). Also included are the global reference markets of France (FRA) and Germany (GER), UK (UK) and US (US).

\begin{tabular}{|c|c|c|c|c|c|c|c|c|c|c|c|c|c|c|}
\hline & BAH & EGY & JOR & KUW & LEB & MOR & OMA & QAT & TUN & UAE & UK & US & FRA & GER \\
\hline $\mathrm{BAH}$ & 1 & & & & & & & & & & & & & \\
\hline EGY & $0.5757^{* * * *}$ & 1 & & & & & & & & & & & & \\
\hline JOR & $0.3745^{* * *}$ & $0.4345^{* * * *}$ & 1 & & & & & & & & & & & \\
\hline KUW & $0.6537^{* * * *}$ & $0.4177^{* * * *}$ & $0.3260^{* * *}$ & 1 & & & & & & & & & & \\
\hline LEB & $0.3491^{* * *}$ & $0.3861^{* * * *}$ & $0.2921^{* *}$ & 0.1848 & 1 & & & & & & & & & \\
\hline MOR & $0.4228^{* * * *}$ & $0.4866^{* * * *}$ & $0.2878^{* *}$ & $0.3335^{* * *}$ & $0.3908^{* * *}$ & 1 & & & & & & & & \\
\hline TUN & $0.2670^{* *}$ & $0.4225^{* * *}$ & $0.2793 * *$ & 0.1979 & 0.1527 & $0.3675^{* *}$ & $0.3798^{* * *}$ & 0.1715 & 1 & & & & & \\
\hline UAE & $0.5713^{* * * *}$ & $0.5615^{* * * *}$ & $0.5960^{* * *}$ & $0.5062^{* * * *}$ & $0.2604^{* *}$ & $0.2505^{* *}$ & $0.6738^{* * * *}$ & $0.6757^{* * *}$ & $0.2933^{* * *}$ & 1 & & & & \\
\hline UK & $0.4058^{* *}$ & $0.6095 * * *$ & $0.3976 * *$ & $0.5017^{* * *}$ & $0.2649 * *$ & $0.3896^{* *}$ & $0.5628^{* * *}$ & $0.5622 * * *$ & $0.3915^{* *}$ & $0.6112^{* * *}$ & 1 & & & \\
\hline US & $0.4279 * * *$ & $0.5650^{* * * *}$ & $0.3960^{* *}$ & $0.5335^{* * *}$ & $0.2375^{*}$ & $0.3172^{* *}$ & $0.5013^{* * *}$ & $0.5516^{* * *}$ & $0.3798^{* *}$ & $0.5947^{* * *}$ & $0.8822 * * *$ & 1 & & \\
\hline FRA & $0.3742^{* *}$ & $0.5972^{* * *}$ & $0.3545^{* *}$ & $0.4058^{* *}$ & $0.2589 * *$ & $0.4340^{* *}$ & $0.4745^{* *}$ & $0.5587^{* * *}$ & $0.3856^{* *}$ & $0.5605^{* * *}$ & $0.9111^{* * *}$ & $0.8854^{* * * *}$ & 1 & \\
\hline
\end{tabular}

Note: ${ }^{*}{ }^{* *},{ }^{* * *}$ denote significance at $10 \%, 5 \%$ and $1 \%$ respectively

Table 3. Spillover Effects (France)

Table 3 reports spillover effects from France market returns to MENA market returns. In table are MENA markets of Bahrain (BAH), Egypt (Egypt), Jordan (JOR), Kuwait (KUW), Lebanon (LEB), Morocco (MOR), Oman (OMA), Qatar (QTR), Tunisia (TUN), United Arab Emirates (UAE). Global reference market is France (FRA).

\begin{tabular}{lllllllllll}
\hline Coefficient & BAH & EGY & JOR & KUW & LEB & MOR & OMA & QAT & TUN & UAE \\
\hline$C$ & -0.0061 & 0.0182 & -0.0112 & 0.0087 & 0.0009 & $0.0192^{* *}$ & 0.0035 & 0.0059 & 0.0102 & -0.0205 \\
$\alpha_{0}$ & 0.0011 & 0.0062 & 0.0023 & $0.0006^{* *}$ & $0.0008^{* *}$ & $0.0026^{* *}$ & 0.0010 & $0.0053^{* * *}$ & $0.0002^{* * *}$ & 0.0040 \\
$\alpha_{l}$ & -0.0140 & 0.2255 & 0.2314 & $-0.1762^{*}$ & $0.3379^{* *}$ & 0.1610 & 0.0536 & $0.6168^{* *}$ & $-0.1323^{* *}$ & $-0.1318^{* * *}$ \\
$\beta$ & 0.4652 & -0.2024 & 0.0811 & $0.9104^{* * *}$ & $0.7051^{* * *}$ & -0.1542 & 0.4731 & $-0.1926^{* *}$ & $1.0099^{* * *}$ & $0.4799^{*}$ \\
$\psi$ & 0.4045 & 0.7171 & 0.0514 & $0.2548^{* * *}$ & $-0.1185^{* *}$ & $0.4282^{*}$ & 0.1982 & 0.1189 & $0.0381^{* *}$ & 0.6079 \\
\hline
\end{tabular}

Note: ${ }^{*},{ }^{*},{ }^{* * *}$ denote significance at $10 \%, 5 \%$ and $1 \%$ respectively

Table 4. Spillover Effects (Germany)

Table 4 reports spillover effects from France market returns to MENA market returns. In table are MENA markets of Bahrain (BAH), Egypt (Egypt), Jordan (JOR), Kuwait (KUW), Lebanon (LEB), Morocco (MOR), Oman (OMA), Qatar (QTR), Tunisia (TUN), United Arab Emirates (UAE). Global reference market is Germany (GER).

\begin{tabular}{lllllllllll}
\hline Coefficient & BAH & EGY & JOR & KUW & LEB & MOR & OMA & QAT & TUN & UAE \\
\hline$C$ & -0.0066 & 0.0155 & -0.0106 & 0.0074 & 0.0014 & $0.0224^{* *}$ & 0.0062 & -0.0001 & 0.0050 & $-0.0154^{* *}$ \\
$\alpha_{0}$ & 0.0013 & 0.0054 & 0.0019 & $0.0005^{* *}$ & 0.0007 & $0.0023^{* *}$ & 0.0023 & 0.0029 & $0.0004^{* * *}$ & 0.0038 \\
$\alpha_{1}$ & -0.0659 & 0.1522 & 0.1939 & $-0.1522^{* * *}$ & $0.2058^{*}$ & -0.0123 & -0.0807 & -0.0571 & $-0.1284^{* *}$ & $-0.1304^{* *}$ \\
$B$ & 0.4053 & -0.0652 & 0.1810 & $0.8839^{* * *}$ & $0.6973^{* * *}$ & -0.0205 & 0.1444 & 0.5576 & $0.9538^{* * *}$ & $0.4706^{* *}$ \\
$\Psi$ & 0.4346 & 0.6864 & 0.0653 & $0.1996^{* *}$ & 0.0233 & $0.5109^{*}$ & $0.2556^{* *}$ & 0.3228 & $0.0332^{* *}$ & 0.5763 \\
\hline
\end{tabular}

Note: ${ }^{*}, * *, * *$ denote significance at $10 \%, 5 \%$ and $1 \%$ respectively 
Table 5. Spillover Effects (UK)

Table 5 reports spillover effects from France market returns to MENA market returns. In table are MENA markets of Bahrain (BAH), Egypt (Egypt), Jordan (JOR), Kuwait (KUW), Lebanon (LEB), Morocco (MOR), Oman (OMA), Qatar (QTR), Tunisia (TUN), United Arab Emirates (UAE). Global reference market is UK (UK).

\begin{tabular}{lllllllllll}
\hline Coefficient & BAH & EGY & JOR & KUW & LEB & MOR & OMA & QAT & TUN & UAE \\
\hline$C$ & -0.0052 & 0.0165 & -0.0105 & 0.0056 & -0.0019 & $0.0192^{* *}$ & 0.0030 & 0.0053 & 0.0074 & $-0.0225^{* *}$ \\
$\alpha_{0}$ & 0.0013 & $0.0128^{* * *}$ & 0.0019 & $0.0004^{* *}$ & -0.0001 & $0.0027^{*}$ & 0.0010 & $0.0051^{* *}$ & $0.0003^{* *}$ & 0.0025 \\
$\alpha_{1}$ & 0.1395 & 0.0791 & 0.1589 & $-0.1434^{* * *}$ & $-0.1057^{* *}$ & 0.0702 & -0.1070 & $0.5944^{* *}$ & $-0.1460^{* * *}$ & $-0.1422^{* *}$ \\
$\beta$ & 0.4918 & $-0.7256^{* * *}$ & 0.1647 & $0.9492^{* * *}$ & $1.0625^{* * *}$ & -0.1259 & 0.4350 & $-0.1910^{* *}$ & $0.9830^{* * *}$ & $0.7306^{* *}$ \\
$\psi$ & 0.1828 & $0.6085^{* *}$ & 0.1500 & $0.2214^{* * *}$ & 0.0561 & $0.8259^{*}$ & 0.5603 & 0.1477 & $0.0577 * * *$ & 0.6074 \\
\hline Note * ***** denote significance at $10 \%, 5 \%$ and $1 \%$ respectively & & & & & & &
\end{tabular}

Table 6. Spillover Effects (US)

Table 6 reports spillover effects from France market returns to MENA market returns. In table are MENA markets of Bahrain (BAH), Egypt (Egypt), Jordan (JOR), Kuwait (KUW), Lebanon (LEB), Morocco (MOR), Oman (OMA), Qatar (QTR), Tunisia (TUN), United Arab Emirates (UAE). Global reference market is US (US).

\begin{tabular}{lllllllllll}
\hline Coefficient & BAH & EGY & JOR & KUW & LEB & MOR & OMA & QAT & TUN & UAE \\
\hline$C$ & -0.0070 & 0.0146 & -0.0108 & 0.0041 & 0.0013 & $0.0217^{* *}$ & 0.0028 & 0.0069 & 0.0055 & $-0.0229^{* *}$ \\
$\alpha_{0}$ & 0.0014 & 0.0052 & 0.0022 & $0.0007^{* *}$ & 0.0007 & $0.0037^{* *}$ & 0.0013 & $0.0065^{* *}$ & $0.0005^{* * *}$ & 0.0039 \\
$\alpha_{1}$ & 0.0528 & 0.3622 & 0.1746 & $-0.1626^{* *}$ & $0.2147^{* *}$ & -0.0244 & 0.0304 & $0.4242^{* *}$ & $-0.1282^{* *}$ & $-0.1393^{* *}$ \\
$\beta$ & 0.4062 & -0.0849 & 0.1105 & $0.9109^{* * *}$ & $0.6928^{* * *}$ & -0.2094 & 0.3958 & $-0.3030^{*}$ & $0.9178^{* * *}$ & $0.5005^{*}$ \\
$\psi$ & 0.6216 & 0.9916 & 0.1515 & $0.3770^{* * *}$ & 0.0383 & 1.0052 & 0.4859 & 0.3823 & $0.0886^{* *}$ & 1.2752 \\
\hline
\end{tabular}

Note: ${ }^{*},{ }^{* *},{ }^{* *}$ denote significance at $10 \%, 5 \%$ and $1 \%$ respectively

Table 7. News Effect Results (France)

Table 7 reports news effect results with France as a reference country. In table are MENA markets of Bahrain (BAH), Egypt (Egypt), Jordan (JOR), Kuwait (KUW), Lebanon (LEB), Morocco (MOR), Oman (OMA), Qatar (QTR), Tunisia (TUN), United Arab Emirates (UAE). Global reference market is France (FRA).

\begin{tabular}{lllllllllll}
\hline Coefficient & BAH & EGY & JOR & KUW & LEB & MOR & OMA & QAT & TUN & UAE \\
\hline$C$ & -0.0037 & $0.0197^{* *}$ & -0.0064 & 0.0120 & $-0.0076^{* *}$ & $0.0195^{* *}$ & 0.0053 & -0.0041 & -0.0008 & $-0.0161^{* *}$ \\
$\alpha_{0}$ & $0.0022^{* *}$ & $0.0101^{* *}$ & $-0.0006^{* *}$ & 0.0024 & $0.0026^{* *}$ & $0.0028^{* *}$ & $0.0028^{*}$ & $0.0056^{* *}$ & 0.0024 & $0.0071^{* *}$ \\
$\beta$ & -0.0987 & 0.1189 & -0.0513 & $-0.1354^{* *}$ & $0.9057^{* *}$ & 0.0379 & 0.1824 & -0.0816 & $-0.1041^{*}$ & $-0.0829^{*}$ \\
$\alpha_{1}$ & $0.9473^{*}$ & 0.2498 & 0.0144 & 0.2542 & $-0.6674^{*}$ & -0.1265 & 0.5225 & 0.5890 & -0.0229 & 0.2378 \\
$\alpha_{2}$ & $0.2565^{* *}$ & $-0.4840^{* *}$ & $0.9792^{* * *}$ & $0.6404^{* *}$ & $0.3787^{* * *}$ & 0.2665 & 0.1788 & $0.4004^{* *}$ & 0.5832 & 0.3075 \\
$\psi 1$ & -0.0001 & $-0.0038^{* *}$ & $0.0016^{* *}$ & -0.0022 & $-0.0028^{* *}$ & -0.0018 & $-0.0025^{* *}$ & $-0.0049^{* *}$ & $-0.0018^{*}$ & $-0.0051^{* *}$ \\
$\psi 2$ & -0.0833 & 0.6834 & -0.0065 & 0.1621 & 0.0529 & 0.2825 & 0.0802 & 0.1593 & $0.0562^{* *}$ & 0.2549 \\
\hline Note: * **,*** denote significance at $10 \%, 5 \%$ and $1 \%$ respectively & & & & & &
\end{tabular}


Table 8. News Effect Results (Germany)

Table 8 reports news effect results with Germany as a reference country. In table are MENA markets of Bahrain (BAH), Egypt (Egypt), Jordan (JOR), Kuwait (KUW), Lebanon (LEB), Morocco (MOR), Oman (OMA), Qatar (QTR), Tunisia (TUN), United Arab Emirates (UAE). Global reference market is Germany (GER).

\begin{tabular}{lllllllllll}
\hline Coefficient & BAH & EGY & JOR & KUW & LEB & MOR & OMA & QAT & TUN & UAE \\
\hline$C$ & -0.0021 & 0.0138 & -0.0097 & 0.0055 & $-0.0068^{*}$ & $0.0189^{* *}$ & 0.0039 & -0.0050 & 0.0015 & $-0.0197^{* * *}$ \\
$\alpha_{0}$ & $0.0026^{* *}$ & 0.0059 & 0.0012 & $0.0009^{* *}$ & $0.0020^{* *}$ & 0.0029 & $0.0029^{* *}$ & $0.0041^{* *}$ & 0.0024 & $0.0068^{* *}$ \\
$\beta$ & $-0.1515^{*}$ & 0.0928 & $1.2871^{*}$ & $-0.1425^{* *}$ & $0.5696^{* *}$ & -0.0216 & 0.0507 & -0.0893 & -0.0980 & -0.0542 \\
$\alpha_{I}$ & 0.5021 & 0.1115 & -1.1373 & 0.1444 & $-0.6195^{* *}$ & -0.1011 & -0.0943 & $0.7400^{*}$ & -0.0737 & 0.1985 \\
$\alpha_{2}$ & 0.3770 & 0.0157 & -0.0174 & $0.8680^{* * *}$ & $0.5699^{* * *}$ & 0.2940 & 0.0084 & $0.3907^{*}$ & 0.4932 & 0.2647 \\
$\psi 1$ & -0.0018 & -0.0028 & $0.0020^{*}$ & $-0.0014^{*}$ & $-0.0028^{*}$ & -0.0014 & -0.0015 & -0.0024 & -0.0013 & $-0.0060^{* *}$ \\
$\psi 2$ & 0.1369 & 0.7088 & 0.0529 & $0.1567^{* *}$ & 0.1542 & 0.2194 & $0.2292^{* *}$ & 0.1527 & 0.0701 & 0.2537 \\
\hline Note ****** denote significance at $10^{*} \%, 5 \%$ and $1 \%$ respectively & & & & & &
\end{tabular}

Table 9. News Effect Results (UK)

Table 9 reports news effect results with UK as a reference country. In table are MENA markets of Bahrain (BAH), Egypt (Egypt), Jordan (JOR), Kuwait (KUW), Lebanon (LEB), Morocco (MOR), Oman (OMA), Qatar (QTR), Tunisia (TUN), United Arab Emirates (UAE). Global reference market is UK (UK).

\begin{tabular}{lllllllllll}
\hline Coefficient & BAH & EGY & JOR & KUW & LEB & MOR & OMA & QAT & TUN & UAE \\
\hline$C$ & -0.0070 & 0.0111 & -0.0065 & 0.0126 & -0.0035 & $0.0231^{* *}$ & 0.0023 & -0.0011 & 0.0084 & $-0.0201^{* * *}$ \\
$\alpha_{0}$ & $0.0017^{*}$ & $0.0059^{*}$ & $0.0014^{*}$ & $0.0027^{* * *}$ & $0.0025^{* *}$ & 0.0031 & 0.0013 & $0.0034^{* *}$ & $0.0015^{* *}$ & $0.0087^{* *}$ \\
$\beta$ & $-0.1482^{* *}$ & 0.0594 & 1.1421 & $-0.1410^{* *}$ & $0.5929^{* *}$ & -0.0323 & -0.0602 & -0.1164 & $-0.1584^{* * *}$ & -0.0202 \\
$\alpha_{1}$ & $0.7230^{*}$ & 0.1562 & -1.0843 & 0.4614 & $-0.5862^{* *}$ & -0.1040 & -0.0113 & 0.7341 & -0.0740 & 0.3687 \\
$\alpha_{2}$ & $0.4373^{* *}$ & 0.2553 & -0.1566 & 0.4107 & $0.5122^{* * *}$ & 0.0563 & 0.3892 & $0.4347^{*}$ & $0.8765^{* * *}$ & 0.0450 \\
$\psi 1$ & 0.0004 & -0.0046 & $0.0042^{* *}$ & $-0.0020^{* *}$ & $-0.0032^{* *}$ & -0.0001 & -0.0008 & -0.0008 & $-0.0017^{* *}$ & $-0.0084^{* *}$ \\
$\psi 2$ & -0.1254 & 0.7599 & 0.0493 & 0.3408 & 0.2874 & 0.5803 & 0.6123 & 0.1045 & $0.1370^{* *}$ & $1.2344^{*}$ \\
\hline
\end{tabular}

Note: ${ }^{*}, * *, * *$ denote significance at $10 \%, 5 \%$ and $1 \%$ respectively

Table 10. News Effect Results (US)

Table 10 reports news effect results with US as a reference country. In table are MENA markets of Bahrain (BAH), Egypt (Egypt), Jordan (JOR), Kuwait (KUW), Lebanon (LEB), Morocco (MOR), Oman (OMA), Qatar (QTR), Tunisia (TUN), United Arab Emirates (UAE). Global reference market is US (US).

\begin{tabular}{|c|c|c|c|c|c|c|c|c|c|c|}
\hline Coefficient & BAH & EGY & JOR & KUW & LEB & MOR & OMA & QAT & TUN & UAE \\
\hline$C$ & -0.0004 & 0.0118 & -0.0077 & 0.0083 & -0.0065 & $0.0205^{*}$ & 0.0055 & 0.0002 & -0.0002 & $-0.0254^{* *}$ \\
\hline$\alpha_{0}$ & $0.0015^{* *}$ & 0.0067 & $0.0015^{*}$ & $0.0013^{* *}$ & $0.0026^{* *}$ & 0.0031 & 0.0023 & $0.0035^{* *}$ & $0.0019^{* *}$ & $0.0076^{* *}$ \\
\hline$\beta$ & $-0.1198 * *$ & 0.0921 & 0.8765 & $-0.1701^{* *}$ & $0.6233^{* *}$ & -0.0418 & 0.0848 & -0.1189 & -0.1502 & -0.0664 \\
\hline$\alpha_{I}$ & $0.9061 *$ & 0.1304 & -0.8179 & 0.2483 & $-0.6972^{* *}$ & -0.1129 & 0.3085 & 0.6799 & -0.1382 & 0.1584 \\
\hline$\alpha_{2}$ & $0.2979 * *$ & 0.0915 & -0.1663 & $0.7375^{* *}$ & $0.4949 * * *$ & 0.2834 & 0.1728 & $0.4465^{* *}$ & $0.7688^{* * *}$ & 0.2490 \\
\hline$\psi 1$ & 0.0007 & -0.0040 & 0.0043 & -0.0013 & $-0.0027^{*}$ & -0.0007 & -0.0013 & -0.0006 & $-0.0017 * *$ & $-0.0058 * *$ \\
\hline$\psi 2$ & -0.0848 & 1.2486 & 0.0330 & 0.5088 & 0.3970 & 0.4185 & 0.4053 & 0.0796 & $0.2219 * *$ & 0.9497 \\
\hline
\end{tabular}

